\title{
ARTICLE Isosibiricin inhibits microglial activation by targeting the dopamine D1/D2 receptor-dependent NLRP3/caspase-1 inflammasome pathway
}

\author{
Yan-hang Wang ${ }^{1}$, Hai-ning Lv ${ }^{1}$, Qing-hua Cui ${ }^{2}$, Peng-fei Tu' ${ }^{1}$, Yong Jiang ${ }^{1}$ and Ke-wu Zeng ${ }^{1}$
}

\begin{abstract}
Microglia-mediated neuroinflammation is a crucial risk factor for neurological disorders. Recently, dopamine receptors have been found to be involved in multiple immunopathological processes and considered as valuable therapeutic targets for inflammationassociated neurologic diseases. In this study we investigated the anti-neuroinflammation effect of isosibiricin, a natural coumarin compound isolated from medicinal plant Murraya exotica. We showed that isosibiricin (10-50 $\mu \mathrm{M})$ dose-dependently inhibited lipopolysaccharide (LPS)-induced BV-2 microglia activation, evidenced by the decreased expression of inflammatory mediators, including nitrite oxide (NO), tumour necrosis factor-a (TNF- $\alpha$ ), interleukin-6 (IL-6), interleukin-1 $\beta$ (IL-1 $\beta$ ) and interleukin-18 (IL-18). By using transcriptomics coupled with bioinformatics analysis, we revealed that isosibiricin treatment mainly affect dopamine receptor signalling pathway. We further demonstrated that isosibiricin upregulated the expression of dopamine D1/2 receptors in LPStreated BV-2 cells, resulting in inhibitory effect on nucleotide binding domain-like receptor protein 3 (NLRP3)/caspase-1 inflammasome pathway. Treatment with dopamine D1/2 receptor antagonists SCH $23390(1 \mu \mathrm{M})$ or sultopride $(1 \mu \mathrm{M})$ could reverse the inhibitory effects of isosibiricin on NLRP3 expression as well as the cleavages of caspase- 1 and IL-1 $\beta$. Collectively, this study demonstrates a promising therapeutic strategy for neuroinflammation by targeting dopamine D1/2 receptors.
\end{abstract}

Keywords: isosibiricin; natural product; neuroinflammation; dopamine D1/2 receptors; inflammatory mediators; NLRP3 inflammasome pathway

Acta Pharmacologica Sinica (2020) 41:173-180; https://doi.org/10.1038/s41401-019-0296-7

\section{INTRODUCTION}

Dopamine, as a crucial neurotransmitter, can transmit neuronal signals to regulate neurological function by acting on specific dopamine receptors $[1,2]$. Currently, the dopamine receptor family is considered to play a key role in various advanced neural functions, including emotion, reward and autonomic movement [3]. In addition, increasing attention has been paid to the role of the dopamine signal system in immunomodulation and inflammation control $[4,5]$. Previous studies have shown that the genetic and pharmacologic regulation of dopamine receptors can have potential anti-inflammatory effects. For instance, dopamine D2 receptor (DRD2) activation is widely involved in the alleviation of inflammatory bowel diseases [6, 7], pancreatic inflammation [8] and arthritis [9]. Specifically, DRD1/D2 have been found to be widely expressed not only in neurons and T cells [10] but also in microglia [11], indicating that DRD1/D2 might also be potential therapeutic targets for neuroinflammation in the central nervous system (CNS).

Recently, the pharmacologic activation of DRD2 was shown to exert an obvious inhibitory effect on neuroinflammation induced by intracerebral haemorrhage, by regulating the nuclear factor- $\mathrm{kB}$ (NF-KB) signalling pathway [12]. Moreover, new therapies based on DRD2/D3 agonists have been developed for experimental autoimmune encephalomyelitis [13]. Therefore, treating the microglia-derived inflammatory response by targeting dopamine receptors appears to be a promising therapeutic strategy for neuroinflammation. In particular, dopamine receptors have been found to be highly associated with the inflammasome signalling pathway. Some previous research has suggested that spinal cord injury induces inflammatory cytokine production by activating the nucleotide-binding domain-like receptor protein 3 inflammasome pathway, which is significantly suppressed by DRD1 agonists [14]. Moreover, DRD2 can also block NLRP3 inflammasome activation in a $\beta$-arrestin-dependent manner [15]. Collectively, these findings provide a potential therapeutic strategy for treating the neuroinflammatory response by targeting the DRD-mediated inflammasome pathway.

Murraya exotica L. (Rutaceae) has traditionally been used in China for the treatment of infectious diseases and pains [16]. Modern pharmacological studies have suggested that Murraya koenigii and $M$. exotica possess a wide range of biological activities, including anti-inflammatory, antinociceptive, antioxidative stress, anti-mutagenic stress, and chondroprotective and anticancer metastasis effects $[17,18]$. Isosibiricin is a natural

\footnotetext{
${ }^{1}$ State Key Laboratory of Natural and Biomimetic Drugs, School of Pharmaceutical Sciences, Peking University, Beijing 100191, China and ${ }^{2}$ School of Basic Medical Sciences, Peking University Health Science Center, Beijing 100191, China

Correspondence: Yong Jiang (yongjiang@bjmu.edu.cn) or Ke-wu Zeng (ZKW@bjmu.edu.cn)

These authors contributed equally: Yong Jiang, Ke-wu Zeng
}

Received: 22 February 2019 Accepted: 6 August 2019

Published online: 10 September 2019 
bioactive coumarin compound isolated from $M$. exotica. Several studies have indicated that the coumarin derivatives isofraxidin, osthole and urolithin can exert obvious anti-inflammatory activities both in vitro and in vivo [19-21]. Therefore, in this study, we explored the mechanism of the anti-neuroinflammatory effects of isosibiricin in a BV-2 microglial model and highlighted that isosibiricin can significantly inhibit the production of multiple inflammatory mediators induced by bacterial lipopolysaccharide stimulation via targeting the DRD1/D2-dependent inflammasome pathway, providing a potential therapeutic strategy for inflammation-related neurological disorders.

\section{MATERIALS AND METHODS}

Chemicals

Isosibiricin $\left(\mathrm{C}_{16} \mathrm{H}_{18} \mathrm{ClO}_{5}\right.$; relative molecular mass, 290.32) was isolated from M. exotica by our group. SCH 23390 and sultopride were obtained from MedChem Express (Shanghai, China). Nigericin sodium salt was obtained from BioRuler (Beijing, China). Lipopolysaccharide (LPS) from Escherichia coli O55:B5 was obtained from Sigma-Aldrich (St. Louis, MO, USA). Polyvinylidene difluoride (PVDF) membranes were obtained from Merck Millipore (Kenilworth, NJ, USA). Antibodies against pro-caspase-1, caspase-1, pro-interleukin (IL)-1 $\beta$, IL-1 $\beta$, NLRP3, cyclooxygenase-2 (COX-2), nitric oxide synthase (iNOS), glyceraldehyde-3-phosphate dehydrogenase $(\mathrm{GAPDH})$, rabbit $\lg \mathrm{G}$ and mouse $\lg \mathrm{G}$ were obtained from Cell Signalling Technology (Beverly, MA, USA). Antibodies against IL-18 were obtained from Bioway (Beijing, China). Antibodies against DRD1 and DRD2 were obtained from Bioss (Beijing, China).

\section{Mouse strains}

Balb/c mice (6-7 weeks old) were purchased from the VITAL RIVER Laboratories (Beijing, China). All mice were raised in a specific pathogen-free environment.

\section{Cell culture}

The BV-2 cell line was purchased from the Cell Bank of Peking Union Medical College in China. The cells were cultured in Dulbecco's modified Eagle's medium containing $10 \%$ fetal bovine serum, $100 \mathrm{U} / \mathrm{mL}$ penicillin and $100 \mathrm{mg} / \mathrm{mL}$ streptomycin. The cell culture conditions were maintained at $37^{\circ} \mathrm{C}$ in a $5 \% \mathrm{CO}_{2}$ incubator under $95 \%$ absolute humidity.

Nitrite oxide analysis

BV-2 cells were treated with isosibiricin $(0,10,20$ and $50 \mu \mathrm{M})$ with or without LPS for $24 \mathrm{~h}$. Then, the supernatants were used to analyse the production of nitrite oxide (NO) with a nitric oxide analysis kit (Jiancheng Bioengineering Institute, Nanjing, China)

Enzyme-linked immunosorbent assay

BV-2 cells were treated with isosibiricin $(0,10,20$ and $50 \mu \mathrm{M})$ with or without LPS. After treatment for $4 \mathrm{~h}, 100 \mu \mathrm{L}$ of the cell supernatants was centrifuged at $2000 \times g$ for $2 \mathrm{~min}$ to evaluate the accumulation of tumour necrosis factor-a (TNF-a). In addition, $100 \mu \mathrm{L}$ of the cell supernatants was also centrifuged at $2000 \times g$ for $2 \mathrm{~min}$ to evaluate IL-6 levels $8 \mathrm{~h}$ after treatment. The two experiments were carried out with enzyme-linked immunosorbent assay (ELISA) kits (ExCell Bio Company, Shanghai, China) following the manufacturer's protocol.

\section{Bioinformatics analysis}

The cells were collected and RNA was extracted by the RNAprep Pure Cell/Bacteria Kit (Tiangen Biotech, Beijing, China). Target analyses were carried out by the Yuanquan Yike Company (Beijing, China). Amino allyl-labelled antisense RNA was prepared and purified prior to hybridization. Purified, coupled antisense RNA was quantified using NanoDrop ND-1000 to explore the targets affected by isosibiricin.

Transcriptome analysis

Pathway analysis [22] on isosibiricin was also performed by the Yuanquan Yike Company. After the targets of isosibiricin were determined by amino allyl-labelled antisense RNA hybridization, Kyoto Encyclopedia of Genes and Genomes (KEGG) pathway enrichment was used to perform the pathway analysis. Signal pathways significantly influenced by isosibiricin compared with LPS were selected.

Western blotting

After treatment, the cells were lysed in ice-cold RIPA buffer containing $1 \%$ protease inhibitors (Macgene, Beijing, China). Whole-cell proteins were collected by centrifugation at $13000 \times g$ for $30 \mathrm{~min}$. The concentration of the total proteins was detected by a protein assay kit (TransGen, Beijing, China). Protein solutions of equal concentration were separated by $10 \%-15 \%$ SDS-polyacrylamide gel electrophoresis and transferred to PVDF membranes. Next, the PVDF membranes were blocked with $5 \%$ skim milk at $25^{\circ} \mathrm{C}$ for $30 \mathrm{~min}$. Subsequently, the membranes were incubated with primary antibodies at $4{ }^{\circ} \mathrm{C}$ for $12 \mathrm{~h}$. After incubation with a second antibody for $1 \mathrm{~h}$, the membranes were developed with SuperSignal West Femto Maximum Sensitivity Substrate. The protein bands were imaged by a Tanon 5200 Imaging Analysis System (Tanon, Shanghai, China). Relative densitometry analysis was carried out by ImageJ software.

\section{Reverse-transcription PCR}

The cells were collected and total RNA was extracted using the RNAprep Pure Cell/Bacteria Kit (Tiangen Biotech, Beijing, China). The mRNA was reverse transcribed using a cDNA synthesis kit (TransGen, Beijing, China). Reverse- transcription PCR (RT-PCR) was performed using a RT-PCR SuperKit (TransGen, Beijing, China) on an Agilent Technologies Stratagene Mx3005P System. A single cycle was carried out at $95^{\circ} \mathrm{C}$ for $30 \mathrm{~s}, 58^{\circ} \mathrm{C}$ for $30 \mathrm{~s}$ and $63^{\circ} \mathrm{C}$ for $30 \mathrm{~s}$, and this cycle was repeated 40 times. The relative transcriptional levels of DRD1 and DRD2 normalized to those of GAPDH was calculated by the comparative $2^{-\Delta \Delta C T}$ method [23].

Dopamine receptor agonist analysis

HEK293 cells stably expressing DRD1/Ga16 were cultured in 96-well plates for $12 \mathrm{~h}$. After the supernatant was removed, Fluo-4/ $\mathrm{AM}$, a calcium fluorescence probe, was added at $37^{\circ} \mathrm{C}$ for $40 \mathrm{~min}$ in an incubator under $95 \%$ absolute humidity. The Fluo-4/AM was removed and a calcium buffer solution was added. FlexStation II was used to measure the levels of Ga16 protein activation induced by isosibiricin $(0,0.01 \mathrm{nM}, 0.1 \mathrm{nM}, 1 \mathrm{nM}, 10 \mathrm{nM}, 100 \mathrm{nM}, 1 \mu \mathrm{M}$ and $10 \mu \mathrm{M})$ at $525 \mathrm{~nm}$. Dopamine was used as a positive control. The $\mathrm{EC}_{50}$ was analysed by GraphPad Prism. All experiments were carried out by the National Center for Drug Screening (Shanghai, China).

\section{Immunohistochemistry}

Nine Balb/c mice were randomly divided into the control, LPS and isosibiricin groups. The isosibiricin group was treated with isosibiricin ( $20 \mathrm{mg} / \mathrm{kg}$ body weight). After $1 \mathrm{~h}$, both the LPS group and the isosibiricin group were injected intraperitoneally with LPS ( $2 \mathrm{mg} / \mathrm{kg}$ body weight). Then, the brain tissues were sectioned and stained with specific antibodies.

Cycle adenosine monophosphate analysis

BV-2 cells were treated with $50 \mu \mathrm{M}$ isosibiricin with or without LPS for $24 \mathrm{~h}$. Then, the cell lysates were used to analyse the level of cycle adenosine monophosphate (CAMP) with a cAMP direct immunoassay kit (Bioway, Beijing, China) 
a<smiles>COc1cc(OC)c2ccc(=O)oc2c1CC(=O)C(C)C</smiles>

Isosibiricin

C

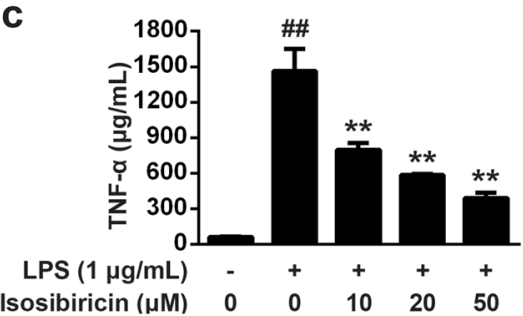

e

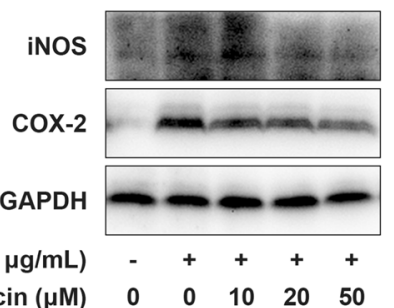

LPS $(1 \mu \mathrm{g} / \mathrm{m}$ Isosibiricin $(\mu \mathrm{M})$ b

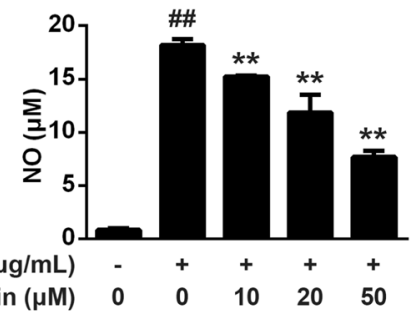

d

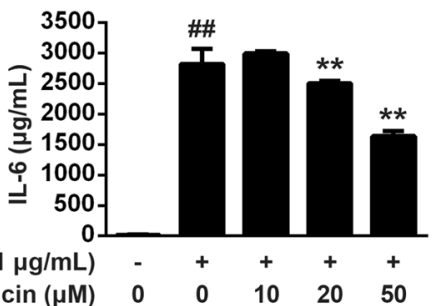

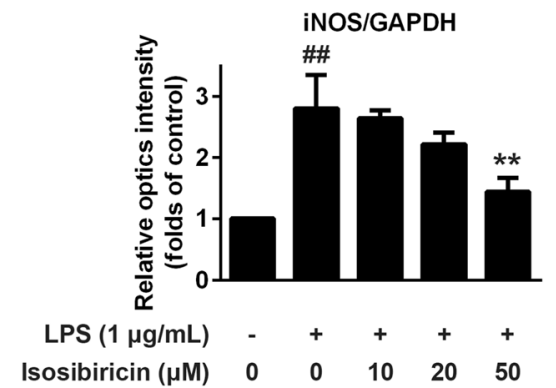

$\begin{array}{cccccc}\text { LPS }(1 \mu \mathrm{g} / \mathrm{mL}) & - & + & + & + & + \\ \text { sosibiricin }(\mu M) & 0 & 0 & 10 & 20 & 50\end{array}$
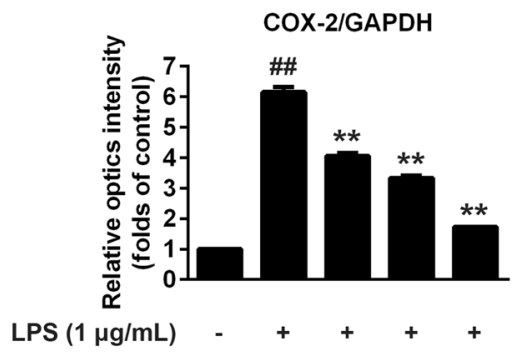

Isosibiricin $(\mu \mathrm{M}) \quad 0 \quad 0 \quad 10 \quad 20 \quad 50$

Fig. 1 Isosibiricin inhibits the productions of inflammatory mediators in LPS-induced BV-2 cells. a The chemical structure of isosibiricin. $\mathbf{b}, \mathbf{c}$, d Isosibiricin inhibited LPS-induced NO (b), TNF- $\alpha$ (c) and IL-6 (d) productions in BV-2 cells. e Isosibiricin inhibited COX-2 and iNOS expressions in BV-2 cells. ${ }^{\# \#} P<0.01$ vs. control group. ${ }^{* *} P<0.01$ vs. LPS group

\section{Statistical analysis}

All experiments were carried out at least three times in triplicate. Statistical analyses were performed by using one-way analysis of variance with GraphPad Prism 6.0 software. Multiple comparisons were performed by comparing the mean of each column with the mean of every other column. Student's $t$-test was used without correcting for multiple comparisons. All data were expressed as the means \pm S.D. A $P$-value $<0.05$ was considered to be significant.

\section{RESULTS}

Isosibiricin inhibits the production of inflammatory mediators in LPS-treated BV-2 cells

In this study, the anti-inflammatory effect of isosibiricin (Fig. 1a) was measured by using an NO release assay. As shown in Fig. 1b, LPS obviously stimulated NO release, which was significantly inhibited by isosibiricin $(10,20$ and $50 \mu \mathrm{M})$ in a concentrationdependent manner. To evaluate the effect of isosibiricin on other inflammatory factors, the levels of TNF- $a$ and IL- 6 were further analysed by ELISA. As shown in Fig. 1c, d, TNF-a and IL-6 expression was significantly increased upon LPS treatment; however, isosibiricin $(10,20$ and $50 \mu \mathrm{M})$ inhibited TNF- $a$ and IL-6 production in a concentration-dependent manner. Moreover, COX-2 and iNOS expression was markedly upregulated in LPStreated BV-2 cells, and isosibiricin reduced COX-2 and iNOS expression in a concentration-dependent manner (Fig. 1e). Taken together, these findings indicated that isosibiricin can attenuate neuroinflammation by inhibiting the expression of multiple inflammatory mediators in LPS-treated BV-2 cells.

Isosibiricin upregulates DRD1/D2 expression in LPS-treated BV-2 cells and Balb/c mice

To investigate the potential mechanism of the anti-inflammatory effect of isosibiricin, transcriptomics coupled with bioinformatics analysis was performed to explore the anti-inflammatory signalling pathway of isosibiricin in LPS-treated BV-2 cells. The results suggested that 1389 genes, including 615 upregulated genes and 774 downregulated genes (59 genes related to inflammation and 
a

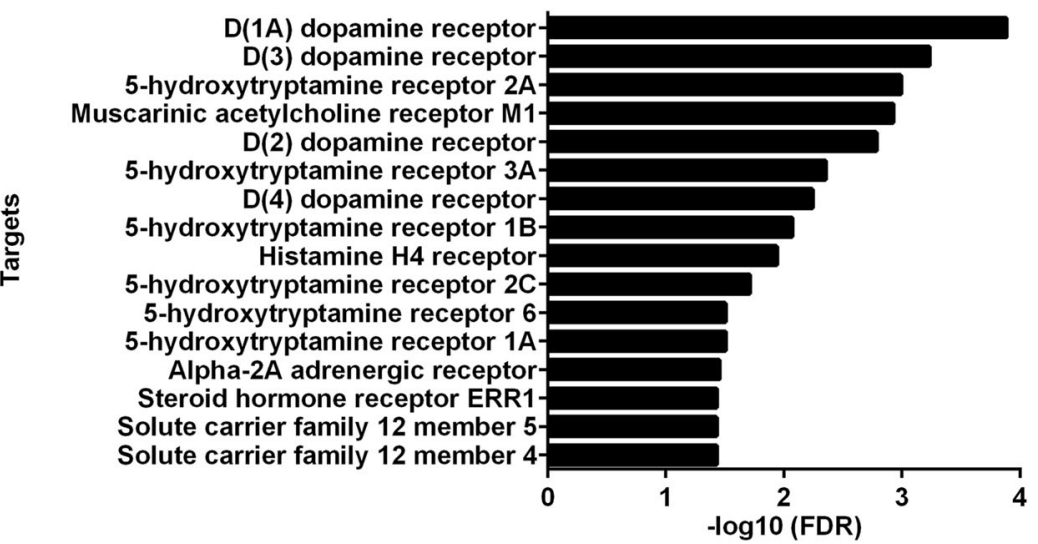

b

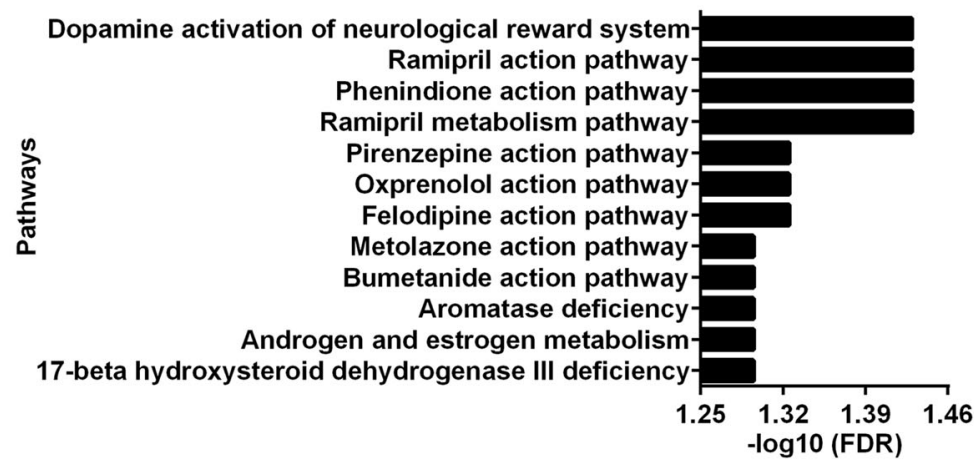

C

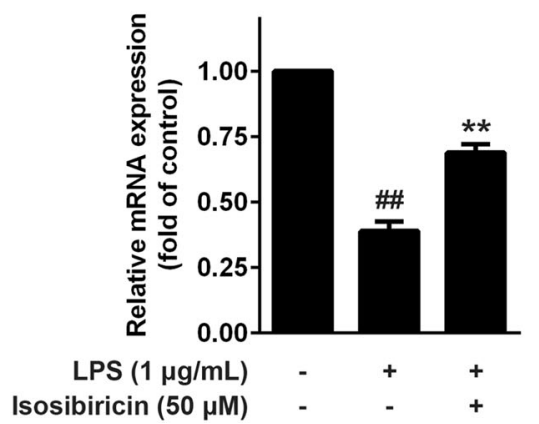

d

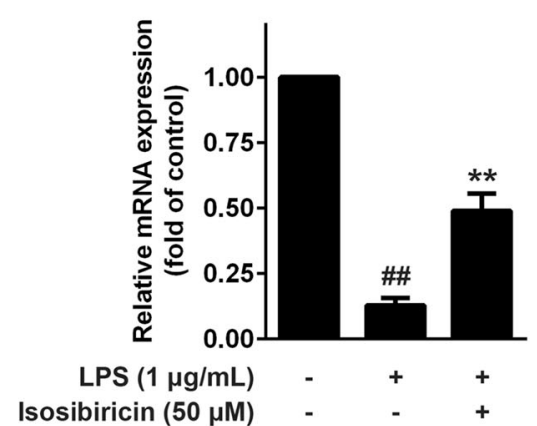

Fig. 2 Isosibiricin upregulates dopamine D1/2 receptors expressions in LPS-induced BV-2 cells. $\mathbf{a}$, b The predicted pathways (a) and targets (b) of isosibiricin inferred by the differential expressed gene-based method. c, d Isosibiricin upregulated dopamine D1 receptors (c) and dopamine D2 receptor (d) expressions in LPS-induced BV-2 cells. ${ }^{\# \#} P<0.01$ vs. control group. ${ }^{* *} P<0.01$ vs. LPS group

32 genes related to the synthesis, storage, release, termination of dopamine and the expression of DRDs) were significantly changed by isosibiricin compared with LPS. Notably, dopamine receptors were most strongly related to isosibiricin treatment (Fig. 2a). Moreover, KEGG pathway analysis was carried out to explore the pathway affected by isosibiricin. As shown in Fig. 2b, dopamine activation of the neurological reward system was strongly influenced by isosibiricin. Therefore, we speculated that isosibiricin might exert an anti-inflammatory effect by targeting the dopamine receptor signalling pathway. Nevertheless, isosibiricin did not directly target or regulate the functions of dopamine receptors (Supplementary Table 1). Thus, we hypothesized that isosibiricin can regulate the expression of dopamine receptors. As shown in Fig. 2c, d, LPS downregulated the mRNA expression of DRD1 and DRD2, and this was significantly reversed by isosibiricin. In addition, isosibiricin also upregulated DRD1/D2 expression in the CA1 region and cortex of LPS-treated Balb/c mice (Supplementary Fig. S1a). Collectively, these observations revealed that isosibiricin can effectively upregulate DRD1 and DRD2 expression in vitro and in vivo, which might represent a crucial antiinflammatory mechanism.

Isosibiricin inhibits the NLRP3/caspase- 1 inflammasome pathway in LPS- or nigericin-treated BV-2 cells and LPS-treated Balb/c mice It has been reported that the expression of the pro-inflammatory mediator IL-1 $\beta$ significantly increases in DRD2-null mice compared with wild-type mice [24]. In addition, DRD1 agonists are able to inactivate the NLRP3 inflammasome pathway [14]. Thus, we detected the effect of isosibiricin on the NLRP3 inflammasome pathway. As shown in Fig. 3a, isosibiricin significantly reduced NLRP3, caspase-1, IL-1 $\beta$ and IL-18 expression in a concentrationdependent manner, indicating that isosibiricin exerts an inhibitory effect on the NLRP3/caspase-1 inflammasome pathway. Moreover, the NLRP3 inflammasome inducer nigericin was used to activate BV-2 cells and we found that nigericin significantly increased NLRP3, caspase-1, IL-1 $\beta$ and IL-18 expression, which was 
a

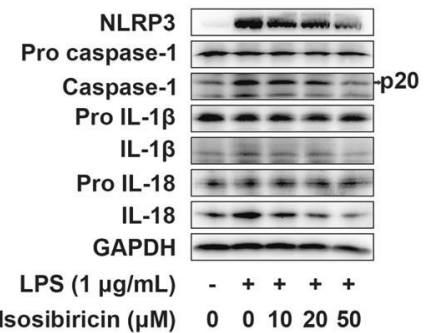

Caspase1/GAPDH IL-1 $\beta / G A P D H$ IL-18/GAPDH

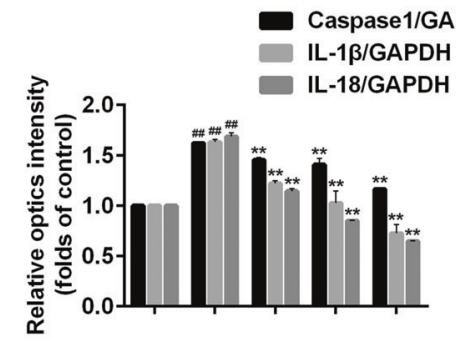

b

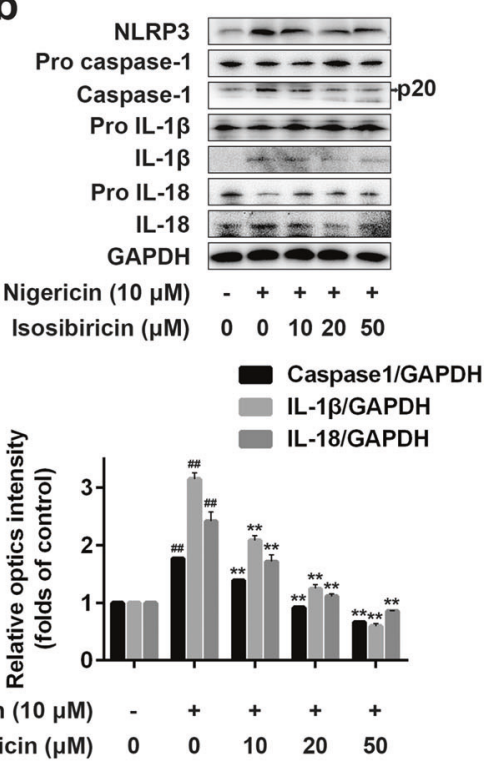

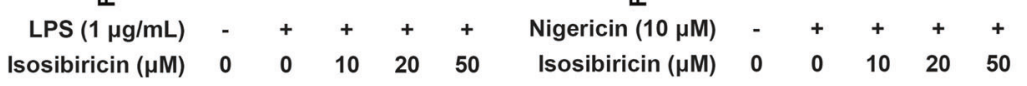

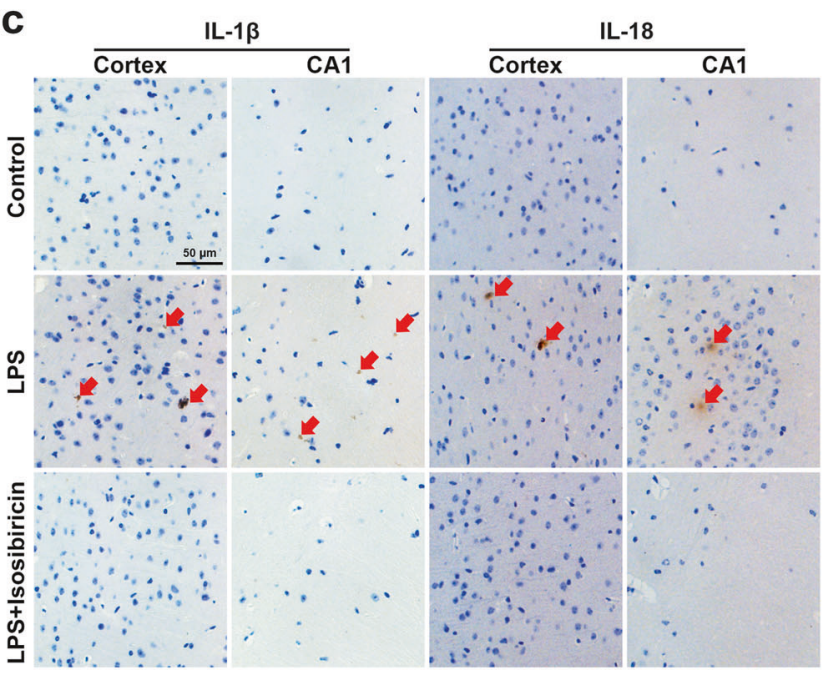

Fig. 3 Isosibiricin inhibits NLRP3/caspase-1 inflammasome pathway in vitro and in vivo. a Isosibiricin inhibited inflammasome-related NLRP3, pro-caspase-1, caspase-1, pro-IL-1 $\beta$, IL-1 $\beta$, pro-IL-18 and IL-18 expressions in LPS-induced BV-2 cells. Quantification for caspase- 1 , IL-1 $\beta$ and IL18 expressions were relative to GAPDH in LPS-induced BV-2 cells. b Isosibiricin inhibited inflammasome-related NLRP3, pro-caspase-1, caspase-1, pro-IL-1 $\beta$, IL-1 $\beta$, pro-IL-18 and IL-18 expressions in nigericin-induced BV-2 cells. Quantification for caspase-1, IL-1 $\beta$ and IL-18 expressions were relative to GAPDH in nigericin-induced BV-2 cells. c Isosibiricin inhibited inflammasome-related IL-1 $\beta$ and IL-18 in the CA1 region and cortex stained with the specific antibodies IL-1 $\beta$ and IL-18. Arrows indicate the activated inflammatory factors. ${ }^{\# \# ~} P<0.01$ vs. control group. ${ }^{*} P<0.01$ vs. LPS group or nigericin group

effectively inhibited by isosibiricin (Fig. 3b) [25]. Animal experiments were also carried out to evaluate the anti-inflammatory effect of isosibiricin. As shown in Fig. 3c, isosibiricin significantly inhibited inflammasome-related IL-1 $\beta$ and IL-18 induced by LPS in the $C A 1$ region and cortex of Balb/c mice. These results suggested that isosibiricin exerts an anti-inflammatory effect via the inhibition of the NLRP3 inflammasome pathway.

DRD1/D2 inhibitors reverse the isosibiricin-mediated inactivation of NLRP3/caspase-1 inflammasome pathway

Considering the effect of isosibiricin on dopamine receptors (Fig. 2c, d) and the inflammasome pathway (Fig. 3a, b), we hypothesized that isosibiricin might inhibit the inflammasome pathway through dopamine receptors. Therefore, DRD1 and DRD2 inhibitors, SCH 23390 and sultopride were used to investigate whether DRD1/D2 are involved in isosibiricinmediated anti-inflammatory effects. We found that the anti- inflammatory effect of isosibiricin was significantly reversed upon treatment with SCH 23390 and sultopride. NLRP3, caspase$1, \mathrm{IL}-1 \beta$ and IL-18 expression was markedly increased by $\mathrm{SCH}$ 23390 and sultopride (Fig. 4a). Furthermore, SCH 23390 and sultopride were also used in nigericin-treated BV-2 cells. Similar to what was observed in the LPS-induced experiment, NLRP3, caspase-1, IL-1 $\beta$ and IL-18 expression was reversed in the $\mathrm{SCH}$ 23390- and sultopride-treated groups compared with the isosibiricin-treated group (Fig. 4d). Taken together, the results suggested that DRD1 and DRD2 inhibitors are able to reverse the isosibiricin-mediated inhibition of the NLRP3/caspase-1 inflammasome pathway.

\section{DISCUSSION}

Dopamine agonists (DAs), such as dopamine, act on dopamine receptors to regulate a great diversity of biological functions [26]. 


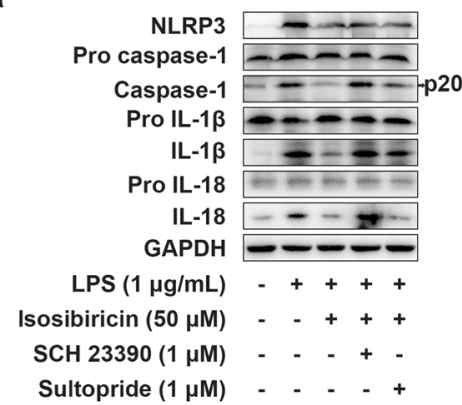

Caspase1/GAPDH IL-1B/GAPDH IL-18/GAPDH

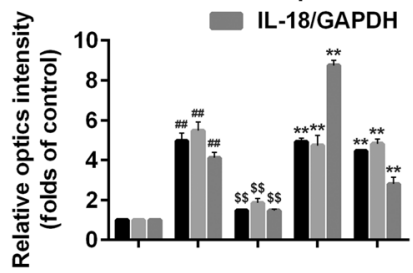

$\operatorname{LPS}(1 \mu \mathrm{g} / \mathrm{mL}) \quad-\quad++++$ Isosibiricin $(50 \mu \mathrm{M})$ - -+++ $\mathrm{SCH} 23390(1 \mu \mathrm{M})$ - $\quad-\quad-\quad+\quad$ - b
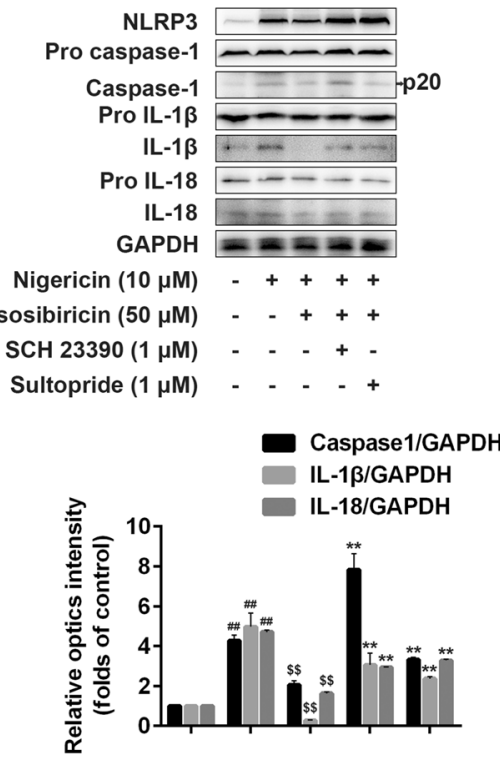

Nigericin $(10 \mu \mathrm{M})-++++$ Isosibiricin $(50 \mu \mathrm{M})$ - -+++ $\mathrm{SCH} 23390(1 \mu \mathrm{M})$ - $\quad-\quad-\quad+\quad$ Sultopride $(1 \mu \mathrm{M})$ - $\quad$ - $\quad$ - $\quad$ - +

Fig. 4 Dopamine D1/2 receptor inhibitors reverse isosibiricin-mediated inhibition of NLRP3/caspase-1 inflammasome pathway. a SCH 23390 and sultopride reversed isosibiricin-mediated inhibition of NLRP3, pro-caspase-1, caspase-1, pro-IL-1 $\beta$, IL-1 $\beta$, pro-IL-18 and IL-18 expressions in LPS-induced BV-2 cells. Quantification for caspase-1, IL-1 $\beta$ and IL-18 expressions was relative to GAPDH in LPS-induced BV-2 cells. b SCH 23390 and sultopride reversed isosibiricin-mediated inhibition of NLRP3, pro-caspase-1, caspase-1, pro-IL-1 $\beta$, IL-1 $\beta$, pro-IL-18 and IL-18 expressions in nigericin-induced BV-2 cells. Quantification for caspase-1, IL-1 $\beta$ and IL-18 expressions was relative to GAPDH in nigericin-induced BV-2 cells.

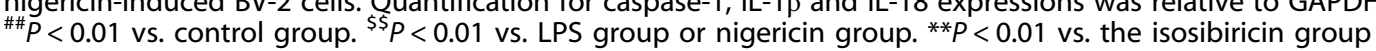

In the past decade, DAs have been mainly used clinically for the treatment of Parkinson's disease and, recently, the development and clinical application of DAs for various other neurological diseases have begun to draw attention from researchers [27, 28]. Neuroinflammation is an inflammatory response in the CNS characterized by increased microglial over-activation [29, 30]. Thus, the development of anti-neuroinflammatory agents is of great importance for the treatment of inflammation-related neurological disorders, such as motor paralysis, amyotrophic lateral sclerosis and dementia [31-33].

In the current study, we reported that isosibiricin exerts a significant anti-neuroinflammatory effect on LPS-treated BV-2 cells. LPS is a common inflammation inducer that is used to investigate different types of inflammatory pathology, such as tissue inflammation [23], vascular inflammation [34] and myocarditis [35]. Dopaminergic neurons play an important role in the pathological process of Parkinson's disease [36], and LPS is widely used to induce neuroinflammation to establish models of Parkinson's disease. In addition, some references have indicated that dopamine receptors are also involved in the regulation of the classical LPS signalling pathway [37-39]. Therefore, LPS was used to induce neuroinflammation and damage dopamine receptors in the substantia nigra [40].

The potential mechanism of isosibiricin may involve the upregulation of DRD1/D2 expression and the further inactivation of the NLRP3/caspase-1 inflammasome pathway, which results in the blockage of the production of multiple inflammatory mediators. In addition, we used Pipeline Pilot to measure the solubility, intestinal absorption and blood-brain barrier (BBB) level of isosibiricin. Isosibiricin exhibited good solubility in water at $25^{\circ} \mathrm{C}$ and was easily absorbed by the intestine. The BBB level was 2 , which means that isosibiricin can pass through the BBB. Thus, our study provides an attractive therapeutic methodology for inflammation-associated neurological disorders, as well as an anti- neuroinflammatory lead compound that may become a clinical candidate.

Dopamine receptors were recently discovered as key therapeutic targets involved in immunoregulation and the inflammatory response [41]. Previously reported active compounds were shown to mainly activate or inhibit dopamine receptors [42, 43]; however, we found that isosibiricin did not directly activate DRD1/D2 but significantly upregulated the expression of DRD1/D2 mRNA, further promoting DRD1/D2-dependent inflammasome signalling pathway inactivation and blocking inflammatory mediator production. In addition, the level of CAMP was regulated by DRD1/D2, but we detected that isosibiricin did not affect the level of cAMP (Supplementary Fig. S1b). These mechanisms are quite different from those of current small molecular regulators, which directly activate DRD1/D2 [44]. However, the molecular mechanism by which DRD mRNA expression is regulated still needs to be explored. We speculate that some transcription factors, such as $N F-K B$, Nrf2 and CREB, might be involved in this process.

Dopamine receptors, including five subtypes from DRD1 to DRD5, are seven-transmembrane-spanning G-protein-coupled receptors $[45,46]$. Based on their structures and pharmacological characteristics, dopamine receptors are divided into two major categories: dopamine D1-like receptors (DRD1 and DRD5) and D2like receptors (DRD2, DRD3, and DRD4) [47]. Notably, the specific DRD inhibitors SCH 23390 (for DRD1) and sultopride (for DRD2) significantly reversed the inhibitory effect of isosibiricin on the NLRP3 signalling pathway, further supporting the observation that isosibiricin suppresses neuroinflammation by blocking the NLRP3/ caspase-1 inflammasome pathway. It is worth mentioning that the regulatory effect of DRD inhibitors on the isosibiricin-dependent inhibition of IL-1 $\beta$ production was more significant in LPS-induced BV-2 cells than in nigericin-induced BV-2 cells. A possible explanation may be that the mechanism by which LPS induces inflammasome signal activation differs from that of nigericin. 
Meanwhile, isosibiricin-mediated anti-neuroinflammation was highly associated with the canonical LPS-induced neuroinflammation pathway. Of course, further studies are needed to elucidate this speculation.

In conclusion, our observations demonstrated that isosibiricin exerts a marked anti-neuroinflammatory effect via targeting the DRD1/D2-dependent NLRP3/caspase-1 inflammasome pathway. This finding indicates that isosibiricin may a promising candidate molecule for that treatment of neuroinflammation, and that DRD1/D2 may be a key target for inflammatory programmes in neurological diseases.

\section{ACKNOWLEDGEMENTS}

This work was financially supported by the National Natural Science Foundation of China (Numbers 81773932, 81530097 and 81222051) and the Drug Innovation Major Project (Number 2018ZX09711001-008-003).

\section{AUTHOR CONTRIBUTIONS}

$\mathrm{KWZ}$, PFT, and YJ designed the research. YHW and HNL conducted majority of the experiments. QHC coordinated the experiments. KWZ and YHW wrote the manuscript. KWZ provided suggestions for the experimental design and manuscript.

\section{ADDITIONAL INFORMATION}

The online version of this article (https://doi.org/10.1038/s41401-019-0296-7) contains supplementary material, which is available to authorized users.

Competing interests: The authors declare no competing interests.

\section{REFERENCES}

1. da Encarnacao TG, Portugal CC, Nogueira CE, Santiago FN, Socodato R, Paes-deCarvalho R. Dopamine promotes ascorbate release from retinal neurons: role of D1 receptors and the exchange protein directly activated by cAMP type 2 (EPAC2). Mol Neurobiol 2018;55:7858-71.

2. Lan Z, Zhang W, Xu J, Zhou M, Chen Y, Zou H, et al. Modulatory effect of dopamine receptor 5 on the neurosecretory Dahlgren cells of the olive flounder, Paralichthys olivaceus. Gen Comp Endocrinol 2018;266:67-77.

3. Vaughn AR, Davis MJ, Sivamani RK, Isseroff RR. A concise review of the conflicting roles of dopamine- 1 versus dopamine- 2 receptors in wound healing. Molecules 2017;23:1-8.

4. Asghar M, George L, Lokhandwala MF. Exercise decreases oxidative stress and inflammation and restores renal dopamine D1 receptor function in old rats. Am J Physiol Ren Physiol 2007;293:F914-9.

5. Nakagome K, Imamura M, Okada H, Kawahata K, Inoue T, Hashimoto $K$, et al Dopamine D1-like receptor antagonist attenuates Th17-mediated immune response and ovalbumin antigen-induced neutrophilic airway inflammation. J Immunol 2011;186:5975-82.

6. Tolstanova G, Deng X, Ahluwalia A, Paunovic B, Prysiazhniuk A, Ostapchenko L, et al. Role of dopamine and D2 dopamine receptor in the pathogenesis of inflammatory bowel disease. Dig Dis Sci 2015;60:2963-75.

7. Magro F, Cunha E, Araujo F, Meireles E, Pereira P, Dinis-Ribeiro M, et al. Dopamine $D 2$ receptor polymorphisms in inflammatory bowel disease and the refractory response to treatment. Dig Dis Sci 2006;51:2039-44.

8. Han X, Li B, Ye X, Mulatibieke T, Wu J, Dai J, et al. Dopamine D2 receptor signalling controls inflammation in acute pancreatitis via a PP2A-dependent Akt/ NF-KB signalling pathway. Br J Pharmacol 2017;174:4751-70.

9. Lu JH, Liu YQ, Deng QW, Peng YP, Qiu YH. Dopamine D2 receptor is involved in alleviation of type II collagen-induced arthritis in mice. Biomed Res Int. 2015;2015:496759. https://doi.org/10.1155/2015/496759.

10. Levite $M$, Marino F, Cosentino M. Dopamine, T cells and multiple sclerosis (MS). J Neural Transm (Vienna) 2017;124:525-42.

11. Kopec AM, Smith CJ, Ayre NR, Sweat SC, Bilbo SD. Microglial dopamine receptor elimination defines sex-specific nucleus accumbens development and social behavior in adolescent rats. Nat Commun 2018;9:3769-84.

12. Zhang Y, Chen Y, Wu J, Manaenko A, Yang P, Tang J, et al. Activation of dopamine $D 2$ receptor suppresses neuroinflammation through aB-crystalline by inhibition of NF-KB nuclear translocation in experimental ICH mice model. Stroke 2015;46:2637-46.

13. Lieberknecht V, Junqueira SC, Cunha MP, Barbosa TA, de Souza LF, Coelho IS, et al. Pramipexole, a dopamine D2/D3 receptor-preferring agonist, prevents experimental autoimmune encephalomyelitis development in mice. Mol Neurobiol 2017;54:1033-45.

14. Jiang W, Huang Y, He F, Liu J, Li M, Sun T, et al. Dopamine D1 receptor agonist A68930 inhibits NLRP3 inflammasome activation, controls inflammation, and alleviates histopathology in a rat model of spinal cord injury. Spine (Philos Pa 1976) 2016;41:E330-4.

15. Du RH, Zhou Y, Xia ML, Lu M, Ding JH, Hu G. a-Synuclein disrupts the antiinflammatory role of DRD2 via interfering $\beta$-arrestin2-TAB1 interaction in astrocytes. J Neuroinflammation 2018;15:258-70.

16. Wei NN, Lv HN, Wu Y, Yang SL, Sun $X Y$, Lai R, et al. Selective activation of nociceptor TRPV1 channel and reversal of inflammatory pain in mice by a novel coumarin derivative Muralatin L from Murraya alata. J Biol Chem 2016;2:640-51.

17. Mani V, Ramasamy K, Abdul Majeed AB. Anti-inflammatory, analgesic and antiulcerogenic effect of total alkaloidal extract from Murraya koenigii leaves in animal models. Food Funct 2013;4:557-67.

18. Wu L, Li P, Wang X, Zhuang Z, Farzaneh F, Xu R. Evaluation of anti-inflammatory and antinociceptive activities of Murraya exotica. Pharm Biol 2010;48:1344-53.

19. Lin J, Li X, Qi W, Yan Y, Chen K, Xue X, et al. Isofraxidin inhibits interleukin-1 $\beta$ induced inflammatory response in human osteoarthritis chondrocytes. Int Immunopharmacol 2018;64:238-45.

20. Jin Y, Qian J, Ju X, Bao X, Li L, Zheng S, et al. Osthole protects against acute lung injury by suppressing NF-KB-dependent inflammation. Mediators Inflamm. 2018;2018:4934592. https://doi.org/10.1155/2018/4934592.

21. Komatsu W, Kishi H, Yagasaki K, Ohhira S. Urolithin A attenuates proinflammatory mediator production by suppressing PI3-K/Akt/NF-KB and JNK/ AP-1 signaling pathways in lipopolysaccharide-stimulated RAW264 macrophages: Possible involvement of NADPH oxidase-derived reactive oxygen species. Eur J Pharmacol 2018;833:411-24.

22. Ji Z, Chao T, Zhang C, Liu Z, Hou L, Wang J, et al. Transcriptome analysis of dairy goat mammary gland tissues from different lactation stages. DNA Cell Biol 2019;2:129-43.

23. Wang LC, Wei WH, Zhang XW, Liu D, Zeng KW, Tu PF. An integrated proteomics and bioinformatics approach reveals the anti-inflammatory mechanism of carnosic acid. Front Pharmacol 2018;9:370-80.

24. Shao W, Zhang SZ, Tang M, Zhang XH, Zhou Z, Yin YQ, et al. Suppression of neuroinflammation by astrocytic dopamine D2 receptors via aB-crystallin. Nature 2013:494:90-4.

25. Schneider KS, Gross CJ, Dreier RF, Saller BS, Mishra R, Gorka O, et al. The inflammasome drives GSDMD-independent secondary pyroptosis and IL-1 release in the absence of caspase-1 protease activity. Cell Rep 2017;21:3846-59.

26. Lanza K, Meadows SM, Chambers NE, Nuss E, Deak MM, Ferré S, et al. Behavioral and cellular dopamine D1 and D3 receptor-mediated synergy: implications for IDOPA-induced dyskinesia. Neuropharmacology 2018;138:304-14.

27. Cahlin BJ, Hedner J, Dahlstrom L. A randomised, open-label, crossover study of the dopamine agonist, pramipexole, in patients with sleep bruxism. J Sleep Res 2017;26:64-72.

28. Calabrese JR, Keck PE Jr, Starace A, Lu K, Ruth A, Laszlovszky I, et al. Efficacy and safety of low- and high-dose cariprazine in acute and mixed mania associated with bipolar I disorder: a double-blind, placebo-controlled study. J Clin Psychiatry 2015;76:284-92.

29. El-Bakoush A, Olajide OA. Formononetin inhibits neuroinflammation and increases estrogen receptor $\beta$ (ER $\beta$ ) protein expression in BV2 microglia. Int Immunopharmacol 2018;61:325-37.

30. Zheng Y, Fang W, Fan S, Liao W, Xiong Y, Liao S, et al. Neurotropin inhibits neuroinflammation via suppressing NF-KB and MAPKs signaling pathways in lipopolysaccharide-stimulated BV2 cells. J Pharmacol Sci 2018;136:242-8.

31. Alberti TB, Barbosa WL, Vieira JL, Raposo NR, Dutra RC. (-)- $\beta$-Caryophyllene, a CB2 receptor-selective phytocannabinoid, suppresses motor paralysis and neuroinflammation in a murine model of multiple sclerosis. Int $\mathrm{J}$ Mol Sci 2017;18:691-704.

32. Malaspina A, Puentes $F$, Amor S. Disease origin and progression in amyotrophic lateral sclerosis: an immunology perspective. Int Immunol 2015;27:117-29.

33. Lykhmus O, Uspenska K, Koval L, Lytovchenko D, Voytenko L, Horid'Ko T, et al. Nstearoylethanolamine protects the brain and improves memory of mice treated with lipopolysaccharide or immunized with the extracellular domain of a7 nicotinic acetylcholine receptor. Int Immunopharmacol 2017;52:290-6.

34. Lee BS, Lee C, Yang S, Park EK, Ku SK, Bae JS. Suppressive effects of pelargonidin on lipopolysaccharide-induced inflammatory responses. Chem Biol Interact 2019;302:67-73.

35. Yang $Y$, Jiang $Z$, Zhuge D. Emodin attenuates lipopolysaccharide-induced injury via down-regulation of mir-223 in H9C2 cells. Int Heart J 2019;60:436-43.

36. He D, Huang B, Fu S, Li Y, Ran X, Liu Y, et al. Tubeimoside I protects dopaminergic neurons against inflammation-mediated damage in lipopolysaccharide (LPS)-evoked model of Parkinson's disease in rats. Int J Mol Sci 2018;19:2242-55. 
37. Kim JY, Tillu DV, Quinn TL, Mejia GL, Shy A, Asiedu MN, et al. Spinal dopaminergic projections control the transition to pathological pain plasticity via a D1/D5mediated mechanism. J Neurosci 2015;35:6307-17.

38. Nakano K, Yamaoka K, Hanami K, Saito K, Sasaguri Y, Yanagihara N, et al. Dopamine induces IL-6-dependent IL-17 production via D1-like receptor on CD4 naive $\mathrm{T}$ cells and D1-like receptor antagonist SCH-23390 inhibits cartilage destruction in a human rheumatoid arthritis/SCID mouse chimera model. J Immunol 2011;186:3745-52.

39. Laengle UW, Markstein R, Schneider V, Roman D. Effects of antiglaucoma drugs GLC756, a novel dopamine D2 agonist and D1 antagonist, and timolol on endotoxininduced TNF-alpha release in serum of rats. Eur J Ophthalmol 2006;16:401-6.

40. Bok E, Chung YC, Kim KS, Baik HH, Shin WH, Jin BK. Modulation of M1/M2 polarization by capsaicin contributes to the survival of dopaminergic neurons in the lipopolysaccharide-lesioned substantia nigra in vivo. Exp Mol Med 2018;50:76-89.

41. Taylor BK, Joshi C, Uppal H. Stimulation of dopamine D2 receptors in the nucleus accumbens inhibits inflammatory pain. Brain Res 2003·987:135-43.
42. Dinkins $M L$, Lallemand $P$, Clemens $S$. Long-term treatment with dopamine $D 3$ receptor agonists induces a behavioral switch that can be rescued by blocking the dopamine D1 receptor. Sleep Med 2017;40:47-52.

43. Thorstensen JR, Tucker MG, Kavanagh JJ. Antagonism of the D2 dopamine receptor enhances tremor but reduces voluntary muscle activation in humans. Neuropharmacology 2018;141:343-52.

44. Cortes M, Malave L, Castello J, Flajolet M, Cenci MA, Friedman E, et al. CK2 oppositely modulates I-DOPA-induced dyskinesia via striatal projection neurons expressing D1 or D2 receptors. J Neurosci 2017;49:11930-46.

45. Wang D, Ji X, Liu J, Li Z, Zhang X. Dopamine receptor subtypes differentially regulate autophagy. Int J Mol Sci 2018;19:1540-55.

46. Kuang ZK, Feng SY, Hu B, Wang D, He SB, Kong DX. Predicting subtype selectivity of dopamine receptor ligands with three-dimensional biologically relevant spectrum. Chem Biol Drug Des 2016;88:859-72.

47. Troppmann B, Balfanz S, Krach C, Baumann A, Blenau W. Characterization of an invertebrate-type dopamine receptor of the American cockroach, Periplaneta americana. Int J Mol Sci 2014;15:629-53. 